\title{
Application of Atomic Force Microscopy in Characterization of Marine Aerosols
}

\author{
Sanja Stevanović ${ }^{1}$, Ana Cvitešić ${ }^{2}$, Vladislava Jovanović ${ }^{1}$, Nikola Batina ${ }^{3}$, Irena Ciglenečki ${ }^{2}$ \\ ${ }^{1}$ ICTM, Department of Electrochemistry, University of Belgrade, Njegoševa 12, Belgrade, Serbia, \\ ${ }^{2}$ Division for Marine and Environmental Research, Ruđer Bošković Institue, Bijenička 54, 10000 \\ Zagreb, Croatia \\ ${ }^{3}$ LNIM, Departamento de Química, CBI,Universidad Autónoma Metropolitana-Iztapalapa, 09340 \\ CDMX, México \\ irena@irb.hr
}

\begin{abstract}
The current knowledge in aerosol science is still incapable to give a real and quantitative assessment of their actual impact on global climate and health. This problem arises from the fact that, until today, there is insufficient knowledge regarding aerosol sources, mechanisms of formation, aerosol properties and chemical composition. In this study, atomic force microscopy (AFM) was applied for characterization/imaging of water soluble fraction of marine aerosols. Obtained results were discussed in terms of water soluble organic matter results obtained by high temperature catalytic oxidation (HTCO) and electrochemistry. Each technique characterized different chemical components of marine aerosols and provided complementary information.
\end{abstract}

Key words: marine aerosols, AFM, organic matter, nanoparticles, Rogoznica Lake

\section{Introduction}

The marine aerosol constitutes one of the most important natural aerosol systems globally. It contributes significantly to the Earth's radiative budget, biogeochemical cycling, impacts on ecosystems and even to regional air quality. Aerosols influence both climate and human health and ultimately influence the quality of freshwater and marine waters [1].

The marine aerosol comprises primary (PMA) and secondary aerosol components $[1,2]$. Considerable advances have been made in the last several years in terms of better understanding of both primary and secondary marine aerosol formation and characterization. In terms of primary marine aerosols, a number of studies have confirmed a significant flux of submicrometre seaspray particles, even down to $10 \mathrm{~nm}$ sizes [2]. For secondary marine aerosol formation, recent advances have identified iodine oxides and isoprene oxidation products, in addition to sulphuric acid, as contributing to formation and growth $[2,3]$. lodine oxides are likely to participate in both nucleation and growth. Since sub-micron aerosol particles constitute a main factor of air pollution, characterization of ultrafine aerosols is of crucial importance for modeling and understanding atmospheric chemistry $[3,4]$. The aerosol size largely determines the behavior of the particles in gas suspensions.
Particles behave differently in different size ranges and are even governed by different physical laws [4]. The optical properties of aerosol particles are determined by their composition, shape and structure.

Following the work on the application of the AFM for the marine ecology studies [5, 6], here AFM has been applied for studying size distribution of nanometer-sized particles in water soluble fraction of marine aerosols adsorbed on the mica surface.

\section{Methodology}

The aerosol samples (aerodynamic diameter < $2.5 \mu \mathrm{m}$ ) were collected on the glass fiber GF/F filters $(\varphi=47 \mathrm{~mm})$ by low volume sampler $\left(2.3 \mathrm{~m}^{3} / \mathrm{h}\right.$, sampling time: $\left.48 \mathrm{~h}\right)$. Before exposure, the filters were pre-combusted at $650^{\circ} \mathrm{C}$ for $5 \mathrm{~h}$ and after the sampling these were carefully packed in aluminum foils (pre-heated at $450^{\circ} \mathrm{C}, 5 \mathrm{~h}$ ) and stored in a freezer until the analysis. Blank filters were prepared in the same way as filters for sampling but without exposure to air. Samplings were performed during winter and spring (January and August 2015) at Rogoznica Lake marine system in the central Dalmatia (Middle Adriatic, $43^{\circ} 32^{\prime} \mathrm{N}$ $15^{\circ} 58^{\prime} \mathrm{E}$, Fig. 1). Rogoznica Lake can be considered as an extreme, naturally eutrophic system which feels all effects of the Adriatic atmospheric and ocean conditions $[6,7]$. The 
climate is Mediterranean, with warm summer and mild winter periods with average temperatures of $8-10^{\circ} \mathrm{C}$ during winter. The whole region is characterized with extensive tourism, with a low impact of industrial activities.

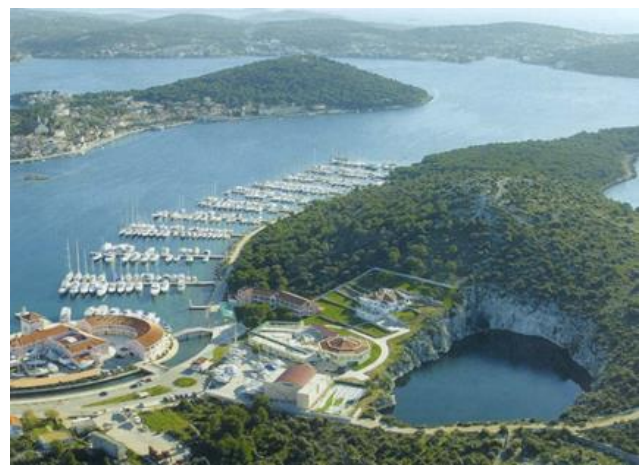

Fig. 1. Airphoto of Rogoznica Lake, Central Dalmatia.

\section{Sample pre-treatment}

The water-soluble aerosol fraction was extracted by placing half of the filters in $0.13-0.2 \mathrm{dm}^{3}$ of high purity deionized MilliQ water (Millipore Corp.) for $24 \mathrm{~h}$, following the work of Frka et al. [8]. The extracts were then filtered through $0.7 \mu \mathrm{m} \mathrm{GF} / \mathrm{F}$ filters pre-combusted at $450^{\circ} \mathrm{C}$ for $5 \mathrm{~h}$ and directly used for electrochemical measurements and WSOC analysis. The samples of the filtered extracts for WSOC analysis were preserved by adding $100 \mu \mathrm{L}$ of $2 \mathrm{gdm}^{-3} \mathrm{HgCl}_{2}$. The extracts for AFM imaging were filtered through $0.02 \mu \mathrm{m}$.

\section{Sample characterization}

NanoScope III A (Veeco, USA) microscope was used to study the morphology of aerosol water suspension (10 $\mu \mathrm{l}$ of suspension) on the mica surface by AFM, which operated in tapping mode under ambient conditions [9]. Silicon probes with a spring constant $20-80 \mathrm{Nm}^{-1}$ were used.

Characterization of organic matter and reduced sulfur species in WSOC fraction was performed by fast, easy performing and sensitive electrochemical method that has been developing in our group for characterization and measurements of surface active substances (SAS) and different reduced sulfur compounds in natural waters [6-8, 10, 11]. Electrochemical measurements were performed with an electrochemical analyzer $\mu$ Autolab-type (Eco Chemie B.V., The Netherlands) equipped with GPES 4.6 software (Eco Chemie B.V., The Netherlands). A standard polarographic Metrohm cell of $50 \mathrm{~cm}^{3}$ equipped with a threeelectrode system was used. A hanging $\mathrm{Hg}$ drop electrode (HMDE, Metrohm, Switzerland) with the surface area $A=0.01245 \mathrm{~cm}^{2}$ was used as a working electrode, an $\mathrm{Ag} / \mathrm{AgCl} / 3 \mathrm{~mol} \mathrm{dm}^{-3} \mathrm{KCl}$ as the reference electrode and a platinum coil as the auxiliary electrode. A saturated solution of $\mathrm{NaCl}$ was added to the WSOC sample to adjust ionic strength of 0.55 moldm$^{-3}$ electrolyte solution prior to the measurement. In the same samples the presence of reduced sulfur species based on acidification step [6, 10, 11] was characterized by use of cathodic stripping voltammetry.

A sensitive high-temperature catalytic oxidation analyzer TOC-VCPH (Shimadzu, Japan) with platinum-coated silica catalyst and a nondispersive infrared detector for $\mathrm{CO}_{2}$ measurements was used for WSOC measurements $[6,10]$. The sample was acidified with $2 \mathrm{M} \mathrm{HCl}$ to $\mathrm{pH} \mathrm{2-3} \mathrm{in} \mathrm{order} \mathrm{to} \mathrm{eliminate} \mathrm{the} \mathrm{inorganic}$ carbonates. The concentration of TOC in each sample was calculated as an average of three to five replicates. The average MilliQ blank was found to be around $0.03 \mathrm{mg} \mathrm{dm}{ }^{-3}$ with relative high reproducibility $(1.6 \%)$.

\section{Results and discussion}

AFM images of water soluble fraction of marine aerosol samples collected in summer and winter seasons are presented as 2D images in Fig. 2. Note dark substrate surface and light color of the NPs. From presented images it is clearly visible significant difference between winter and summer samples that was imaged by AFM. Cross section analysis on the AFM image (Fig. 3) shows manly spherical nanoparticles with diameter of 86.5 to $90.7 \mathrm{~nm}$ in summer sample, while the same analyses revealed NPs with sizes between $63.15 \mathrm{~nm}$ and $56.29 \mathrm{~nm}$ in winter sample (Fig. 3b). On both images particles are well defined, with very similar sizes (diameter and height) and well separated at the surface. They do not show tendency for aggregation. It seems, we are looking some kind of nucleation and growth of particles just on the specific nucleation (adsorption) sites. This can be result of low attraction between the NPs on the surface and in the solution, pointing to type of material which does not show tendency for aggregation. In general, we are considering NPs, which like to adsorb at the mica substrate surface.

On winter AFM images, NPs are considerably smaller. They do not show growth on the surface, and number of particles is considerably lower (for about 30\%) than revealed for the summer image. Electrochemical and HTCO measurements, uphold the AFM results indicating significant difference in the present type of organic matter characterized during the different seasons. 
a

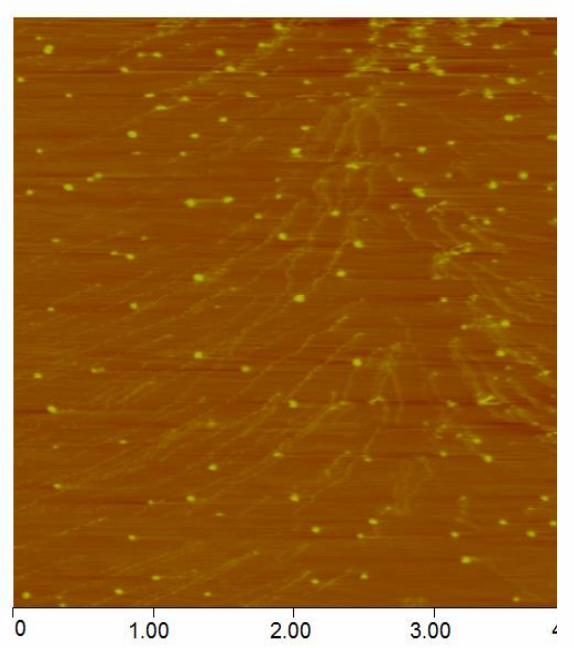

b

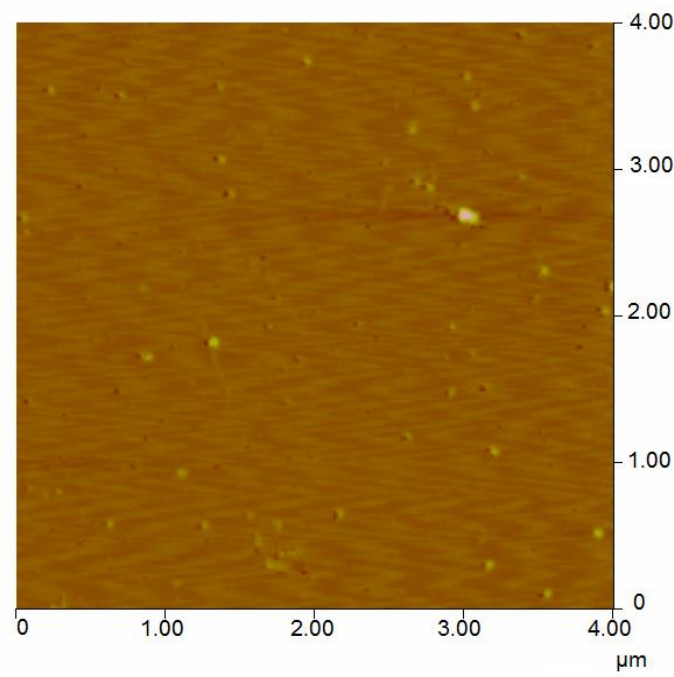

Fig. 2. AFM images of water soluble marine aerosol samples from summer (a) and winter (b) seasons in Central Dalmatia. The image size: $4 \mu \mathrm{m} \times 4 \mu \mathrm{m}$, with z scale of $60 \mathrm{~nm}$.
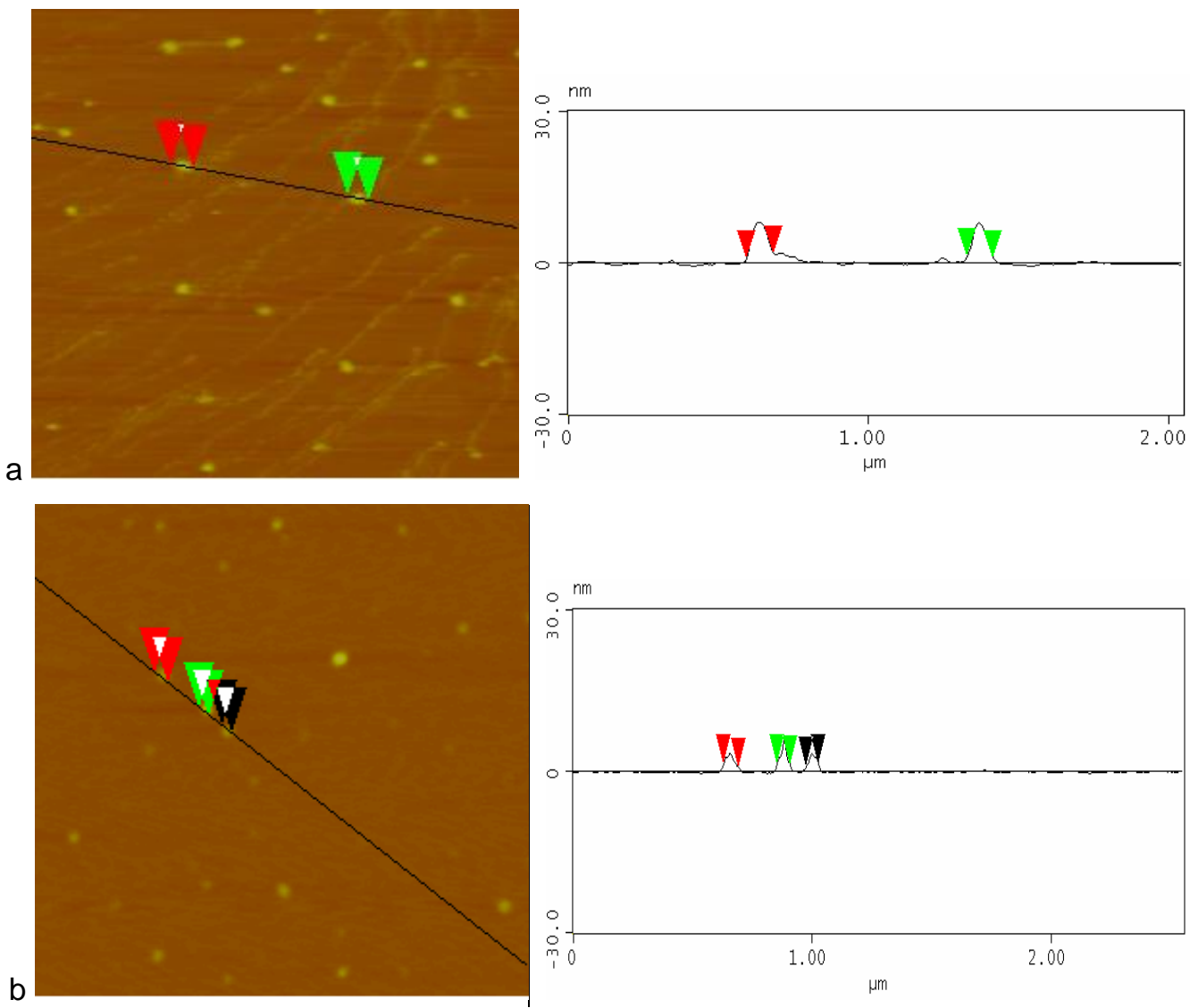

Fig. 3. Cross section analysis on the AFM image, size $2 \mu m \times 2 \mu m \times 60 \mathrm{~nm}$. a) summer sample with mainly spherical NPs with diameter of 86.5 to $90.7 \mathrm{~nm}$; b) winter sample with NPs with diameter of 63.15 to $56.29 \mathrm{~nm}$. 
In summer samples (Figs. 2a, 3a), which due to biological activity were characterized by higher concentration of PM mass (up to $28.4 \mu \mathrm{g} / \mathrm{m}^{3}$ in summer, compared to $17.3 \mathrm{\mu g} / \mathrm{m}^{3}$ in winter), total organic carbon (TOC, average $4,2 \mu \mathrm{g} / \mathrm{m}^{3}$ in summer, and $3.2 \mu \mathrm{g} / \mathrm{m}^{3}$ in winter), water soluble organic carbon (WSOC average $2.8 \mu \mathrm{g} / \mathrm{m}^{3}$ in summer and 1.0 in winter), and its surface active components (SAS, average $0.5 \mu \mathrm{g} / \mathrm{m}^{3}$ in summer and $0.2 \mu \mathrm{g} / \mathrm{m}^{3}$ in winter), presence of higher concentration of NPs with larger sizes (86 and $91 \mathrm{~nm}$ ) were detected. Winter sample (Figs. 2b, 3b), was depleted with organic matter content and in the same time was characterized by smaller NPs (56 and $63 \mathrm{~nm}$ ). In both samples presence of reduced sulphur species were detected in the concentration of around $1 \mathrm{nM}$, what is a detection limit of the used electrochemical method. We assume that quantity and quality of organic matter influence size distribution of recorded nanoparticles.

\section{Conclusion}

This comprehensive study assessment confirmed significant difference between winter and summer samples that was imaged by AFM. In summer samples, which due to biological activity were characterized by higher concentration of PM mass, total organic carbon (TOC), water soluble organic carbon (WSOC), and its surface active components (SAS), presence of higher concentration of nanoparticles with sizes between 86 and $91 \mathrm{~nm}$ were detected. Winter sample depleted with organic matter content was characterized by smaller NPs, with sizes between 56 and $63 \mathrm{~nm}$. We assume that quantity and quality of organic matter influence size distribution of recorded nanoparticles.

AFM offers basic information about size and type of interaction with the studied surface. Studies in the same directions with use of different substrates and solutions could show more details. There is not so many work, neither a general agreement how to characterized by filter collected aerosol NPs by AFM, using in our case so called "solvent" method for sample preparation. Therefore further work is required and planned for more general conclusions.

\section{Acknowledgements}

This work is supported by projects: Croatian Science Foundation, IP-11-2013-1205, SPHERE; Ministry of Education and Science, Republic of Serbia, project No. 172060 and CBI, UAM-I, Mexico.

\section{References}

[1] U. Poschl, Atmospheric Aerosols: Composition, Transformation, Climate and Health Effects, Angew. Chem. Int. Ed. 44, 7520 - 7540 (2005); DOI: 10.1002/anie.200501122.

[2] C. D. O'Dowd, G. DE Leeuw, Marine aerosol production: a review of the current knowledge, Phil. Trans. R. Soc. A 365, 1753-1774 (2007) doi:10.1098/rsta.2007.2043.

[3] K. S. Carslaw, O. Boucher, D. V. Spracklen, G. W. Mann, J. G. L. Rae, S. Woodward, M. Kulmala, A review of natural aerosol interactions and feedbacks within the Earth system, Atmos. Chem. Phys., 10, 1701-1737 (2010).

[4] G. Köllensperger, G. Friedbacher, A. Krammer M. Grasserbauer, Application of atomic force microscopy to particle sizing, Fresenius J Anal Chem 363, 323-332 (1999).

[5] V. Svetličić, V. Žutić, G. Pletikapić, T. Mišić Radić, Marine Polysaccharide Networks and Diatoms at the Nanometric Scale. Int. J. Mol. Sci. 14, 20064-20078 (2013).

[6] M. Marguš, I., Morales-Reyes, E. Bura-Nakić, N. Batina, I. Ciglenečki, The anoxic stress conditions explored at the nanoscale by Atomic Force Microscopy in highly eutrophic and sulfidic marine lake, Cont. Shelf Res.109, 24-34 (2015); 10.1016/j.csr.2015.09.001.

[7] I. Ciglenečki, I. Janeković, M. Marguš E. BuraNakić, M. Carić, Z. Ljubešić, M. Batistić, I. Dupčić, E. Hrustić, R. Garić, The impacts of the extreme weather events on the eutrophicated seawater ecosystem (Rogoznica Lake, Adriatic coast), Cont. Shelf Res.108,144-155 (2015); 10.1016/j.csr.2015.05.007.

[8] S. Frka, J. Dautović, Z. Kozarac, B. Ćosović, A. Hoffer, G. Kiss, Surface-active substances in atmospheric aerosol: an electrochemical approach“, Tellus B. 64, 18490-18502 (2012).

[9] D. Tripković, S. Stevanović, A. Tripković, A. Kowal, V.M.Jovanović, Strustural effect in electrocatalysis: Formic acid oxidation on $\mathrm{Pt}$ electrodeposited on glassy carbon support, J. Electrochem. Soc. 155, B281-B289 (2008).

[10] B. Ćosović, P. Orlović-Leko, Z. Kozarac, Rainwater Dissolved Organic Carbon: Characterization of Surface Active Substances by Electrochemical Method. Electroanalysis 19, 2077-2084 (2007).

[11] B. Ćosović, I. Ciglenečki, D. Viličić, M. Ahel, Distribution and seasonal variability of organic matter in a small eutrophicated salt lake. Estuar. Coast. Shelf Sci. 51, 705-715 (2000).

[12] I. Ciglenečki, B. Ćosović, Electrochemical Determination of Thiosulfate in Seawater in the Presence of Elemental Sulfur and Sulfide, Electroanalysis 9, 775-780 (1997). 